УДК 911.7

\title{
МИГРАЦИЯ МИРОВОГО ЦЕНТРА ЭКОЛОГИЧЕСКОГО НЕБЛАГОПОЛУЧИЯ И “ГЕОЭКОЛОГИЧЕСКИЙ ПЕРЕХОД"
}

\author{
(C) 2020 г. Д. Л. Лопатников* \\ Институт географии РАН, Москва, Россия \\ *e-mail: imartos@mail.ru \\ Поступила в редакцию 09.09.2019 г. \\ После доработки 18.05.2020 г. \\ Принята к публикации 06.06.2020 г.
}

\begin{abstract}
Ухудшение экологической обстановки в Центре мирового хозяйства во второй половине ХХ в. сменилось разнонаправленностью экологических трендов в макрорегионах мира в первые десятилетия XXI в. Межрегиональные и межстрановые сдвиги в экологической обстановке тесно сопряжены с трансформациями в географии мирового хозяйства. Постиндустриальный уклад в высокоразвитых странах ослабил прямую связь между экономическим ростом и его экологическими издержками. Экологически позитивные тренды в этих странах детерминированы экономическими и социальными факторами. Страны мировой Полупериферии выступили очагами догоняющей индустриализации, куда из стран Центра мирового хозяйства сместился главный очаг экологического неблагополучия на планете. Усложнение связей между экономическим ростом и его экологическими последствиями на стыке столетий свидетельствует о начале качественно нового этапа в развитии мирового хозяйства и экологической обстановки на Земле. В ближайшие десятилетия экологическая обстановка в мире будет пространственно усложняться, станет более мозаичной, что, возможно, знаменует начало глобального “геоэкологического перехода” в масштабах всего мирового хозяйства.
\end{abstract} Ключевые слова: эмиссия $\mathrm{CO}_{2}$, территориальная организация мирового хозяйства, экологические
проблемы, экологизация

DOI: $10.31857 / \mathrm{S} 2587556620050106$

\section{ПОСТАНОВКА ПРОБЛЕМЫ}

Во второй половине прошлого века идеи экологического императива вызревали как ответ на вызовы масштабного послевоенного индустриального роста в авангардных странах, сопровождавшегося стремительным ухудшением экологической обстановки. Мейнстрим того времени - экологический алармизм, акцентирующий внимание на катастрофических последствиях воздействия человека на природу и необходимости принятия немедленных решительных мер для спасения цивилизации и планеты. Рост общественного интереса к экологической тематике в последней четверти прошлого века был тесно связан с мощными протестными экологическими движениями, родившимися в 1970-х годах в Западной Европе. Движение "зеленых" с выраженными экологическим императивом в это десятилетие стало мощной движущей силой общественной жизни. Гипотеза глобального потепления климата под воздействием антропогенной эмиссии углекислого стала аксиомой в общественном и особенно в политическом сознании.

Ответом на стремительное обострение экологической ситуации в странах Запада в послевоен- ное тридцатилетие стала концепция устойчивого развития, инициирующая формирование планов и структур для ее реализации, экологизацию всего спектра социально-экономического развития человечества с целью избежать грядущего экологического апокалипсиса.

Наряду с экологизацией общественного сознания в 1970-80-е годы шли важные объективные процессы в высокоразвитых странах. Среди факторов и двигателей перемен следует назвать:

- мировой топливно-энергетический кризис, спровоцировавший рост цен на нефть в шесть раз в период с 1973 по 1981 г., что дало мощный импульс внедрению новых энергосберегающих и несырьеемких технологий;

- переход авангардных стран к постиндустриальному хозяйственному укладу, где ведущую роль в экономике играет нематериальное производство, в 3-4 раза менее энергоемкое и сырьеемкое, чем сфера материального производства;

- формирование в 1970-е годы новой модели международного разделения труда, переход развивающихся стран мировой Полупериферии к производству и экспорту продукции обрабатывающей промышленности, тесно связанное с пере- 
носом грязных производств в страны Полупериферии. Этот фундаментальный процесс был зафиксирован в классической работе П. Диккена "Global shift" [12], первое издание которой вышло в 1986 г.;

- “неолиберальная революция" конца 1970начала 1980-х годов, одним из последствий которой стало свертывание угольной промышленности и сокращение использования угля в энергетике стран Центра мирового хозяйства.

Но все же самое главное заключается в том, что бурный экономический рост в странах Запада в послевоенный период привел к значительному повышению уровня жизни и радикально изменил повестку дня, когда стало “до экологии”. С одной стороны, быстрый экономический рост сопровождался таким же быстрым ухудшением экологической обстановки, с другой - вызвал рост требований населения к экологическим характеристикам качества жизни по мере роста благосостояния. Эти требования стали звучать все сильнее по мере развития гражданского общества, постиндустриализации экономики и становления среднего класса.

Рост экологических притязаний людей по мере улучшения их благосостояния стал одним из законов общественной жсизни постиндустриального времени. Рыночная экономика, используя достижения научно-технического прогресса, включилась в процесс удовлетворения растущего спроса населения на экологические блага. В последние 25-30 лет в высокоразвитых странах идет формирование общества потребления нового типа, общества "экологического потребления". Его становление идет в тесной взаимосвязи с формированием "экологического лобби”. При переходе к постиндустриальной модели хозяйственного уклада в третичном секторе сформировалась группа отраслей хозяйства, жизненно заинтересованных в экологически позитивных характеристиках используемых территорий. К таким отраслям можно отнести туризм, образование, науку, культуру. Опережающими темпами развивается “экологический бизнес". Все это в совокупности привело, без преувеличения, к “экологической революции” в странах Запада и качественному улучшению ключевых параметров состояния окружающей среды.

На стыке столетий общая мирохозяйственная и геоэкологическая картины стали качественно меняться. Экологическая статистика конца прошлого-начала нынешнего века свидетельствует о том, что рост глобальных экологических издержек по базовым показателям в целом стал идти медленнее, чем рост мирового валового продукта. В период с 2000 по 2014 г. мировой ВВП вырос с 6.7 до 13.5 трлн (в долларах 1970 г.), т.е. в два раза. При этом мировые антропогенные выбросы $\mathrm{CO}_{2}$ выросли в 1.6 раза - с 22.6 до 35.7 млрд т [20]. Для ряда индикаторов состояния воздуха заметное за- медление роста наметилось в начале нынешнего века. За период с 2005 по 2010 г. темпы роста выбросов замедлились по сравнению с 2000-2005 гг. для гидрофторуглеродов (ГФУ) - в 1.8 раза, для $\mathrm{SF}_{6}-$ в 2.7 раза, для $\mathrm{CH}_{4}-$ в 1.6 раза, для $\mathrm{CO}_{2}-$ в 1.5 раза [3]. Выявленные снижения темпов роста выбросов свидетельствуют о таких изменениях в мировом хозяйстве, как модернизация производства, увеличение доли возобновляемых источников энергии, создание все большей доли добавленной стоимости интеллектуальным трудом. Однако говорить о том, что это долгосрочный тренд в мировом масштабе, пока было бы преждевременным.

\section{ГИПОТЕЗА ГЛОБАЛЬНОГО "ГЕОЭКОЛОГИЧЕСКОГО ПЕРЕХОДА"}

Одним из результатов отмеченных выше процессов стало то, что мир становится все более и более мозаичным по направленности экологически значимых трендов. Усиливающаяся мозаичность мировой экологической панорамы может служить основанием для выдвижения гипотезы о возможном начале глобального мирохозяйственного “геоэкологического перехода", под которым автор понимает процесс перехода от превалирования экологически негативных антропогенных процессов в мировом хозяйстве через стадию их разнонаправленности к изменению в будущем баланса экологически негативных и позитивных процессов в пользу последних.

По мнению автора, мировое хозяйство вступило в начальную стадию глобального "геоэкологического перехода", после которого в долгосрочной перспективе может последовать стабилизация антропогенной нагрузки на биогеосферу Земли, а в будущем, возможно, даже ее ослабление. При оптимистическом сценарии, такой переход может стать одним из проявлений начала новой эры в отношениях между человеком и природой. Уже сейчас, по мнению автора, его ранняя стадия может служить одним из объяснений наблюдаемого "эффекта откладывающегося экологического апокалипсиса", идея которого проходила красной нитью в “Пределах роста" Римского клуба [15]. Стоит отметить, что подобный переход - одно, но не единственное проявление переходного времени, в которое мы все живем. Долгосрочно он будет теснейшим образом связан с демографическим переходом, последствия которого пока недооценены.

“Геоэкологический переход” - масштабный по времени и глобальный по пространственному охвату процесс. Существует огромный спектр индикаторов, с помощью которых нужно отслеживать смену экологически значимых трендов в мировом хозяйстве - от показателей загрязнения воздуха, водных бассейнов, деградации земель, утилизации твердых бытовых отходов до диагно- 


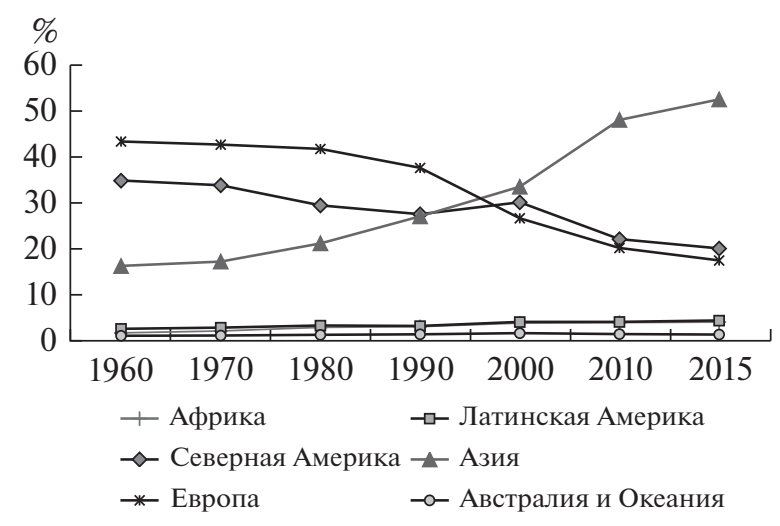

Рис. 1. Выбросы $\mathrm{CO}_{2}$ по регионам мира (в \% от общемировых). Рассчитано автором по: [24].

стики уровня экологического сознания и культуры в различных странах и регионах мира. Чтобы охватить их в рамках одного исследования, нужна, как минимум, монография. Надеемся, что она еще увидит свет. В данной статье автор взял только один, но актуальный и репрезентативный индикатор - антропогенная эмиссия углекислого газа ("газа жизни").

\section{ПРОСТРАНСТВЕННАЯ ТРАНСФОРМАЦИЯ АНТРОПОГЕННОЙ ЭМИССИИ $\mathrm{CO}_{2}$}

Тектонические сдвиги в географии мирового хозяйства, трансформации в его отраслевой и территориальной структурах за последние полвека уже оставили зримый экологический след. Это можно проиллюстрировать на примере антропогенной эмиссии углекислого газа, который, согласно официальной доктрине "Устойчивого развития”, является главным парниковым газом и виновником глобального потепления. Динамика и пространственная трансформация антропогенной эмиссия $\mathrm{CO}_{2}$ может служить одной из иллюстрацией смены тренда с негативного на позитивный через стадию усиления разнонаправленности этого одного из экологически значимых процессов на планете.

С 1960-х годов объемы антропогенных выбросов $\mathrm{CO}_{2}$ бурно росли. Но несмотря на рост абсолютных объемов выбросов, в конце XX в. наметился качественный перелом в ситуации. В 1960 г. душевой показатель антропогенных выбросов $\mathrm{CO}_{2}$ в мире составлял примерно 3 т на человека. Только за одно десятилетие он вырос на 1 т, до 4 т. Вспомним, что это было время пика демографического взрыва в мире. Показательно, что на этот же период приходится "пик экологического алармизма". Но в дальнейшем на то, чтобы прирастить еще одну тонну, даже чуть меньше, ушло почти полвека. То есть мы видим выраженное замедление тренда.
Рост выбросов $\mathrm{CO}_{2}$ стал все больше и больше отставать от роста мировой экономики. Об этом свидетельствуют следующие данные: за период с 1970 по 2015 г. мировой ВВП вырос в 4 раза, а антропогенные выбросы $\mathrm{CO}_{2}-$ в 2.4 раза. Удельные показатели выбросов $\mathrm{CO}_{2}$ на 1 доллар мирового ВВП (в постоянных ценах) неуклонно падают уже полвека. За 1970-2015 гг. они сократились с 0.78 до 0.48 кг, т.е. взаимосвязь между мировым экономическим ростом и антропогенными выбросами $\mathrm{CO}_{2}$ ослабла. При этом произошли кардинально изменились роли стран и регионов мира как источников этих выбросов. В старопромышленных регионах мира - Европе и Северной Америке с 2000-х годов они сокращаются не только по душевым показателям, но и в абсолютном измерении, что принципиально важно. Выбросы в Европе сократились в 1.4-1.5 раза по сравнению с рекордно высоким уровнем 1990 г., снизившись до показателя 1960-х. В ЕС с 1990 по 2014 г. рост ВВП составил $46 \%$, а сокращение антропогенных выбросов $\mathrm{CO}_{2}-23 \%$. Совокупные выбросы 28 стран ЕС уменьшились в 1.3 раза - с 4.3 до 3.4 млрд т. При этом ключевой вклад в уменьшение выбросов $\mathrm{CO}_{2}$ внесли крупнейшие экономики: Германия сократила выбросы на 24\%, Великобритания - на 28, Италия - на 21, Франция - на 15\% [9].

Почти не растут выбросы в Австралии и Океании. Но виден стремительный рост антропогенной эмиссии $\mathrm{CO}_{2}$ в Азии, которая вышла в лидеры с 2010-х годов, на ее долю теперь приходится больше половины мировой эмиссии (рис. 1). Эта беспрецедентная региональная концентрация, судя по тренду, будет и далее усиливаться. При этом даже в Азии показатель выбросов $\mathrm{CO}_{2}$ на 1 доллар ВВП имеет тенденцию к снижению.

Не менее значимые сдвиги наблюдаются и в перераспределении антропогенной эмиссии $\mathrm{CO}_{2}$ между странами (рис. 2). Со времен Промышленной революции и до второй половины XIX в. главным эмитентом антропогенного $\mathrm{CO}_{2}$ выступала Великобритания. С 1880-х годов на первое место вышли США, ставшие крупнейшей индустриальной державой мира эпохи “угля и стали”. Они оставались лидером вплоть до начала XXI в. С 2007 г. Китай опередил США и стал главным эмитентом $\mathrm{CO}_{2}$. Сегодня на долю Китая приходится 30\% выбросов, что превышает суммарную долю США и стран ЕС. В 2015 г. антропогенные выбросы $\mathrm{CO}_{2}$ Китая почти в два раза превышали выбросы США [25]. За 2000-2016 гг. на долю Китая приходилось $60 \%$ мирового прироста антропогенной эмиссии $\mathrm{CO}_{2}$ [20].

Расчеты показали, что на долю стран, где наблюдается тренд на сокращение антропогенной эмиссии $\mathrm{CO}_{2}$, приходится $54.45 \%$ мирового ВВП и $32.14 \%$ мировых выбросов $\mathrm{CO}_{2}$. Но в таких странах проживает только $19.44 \%$ населения планеты. 


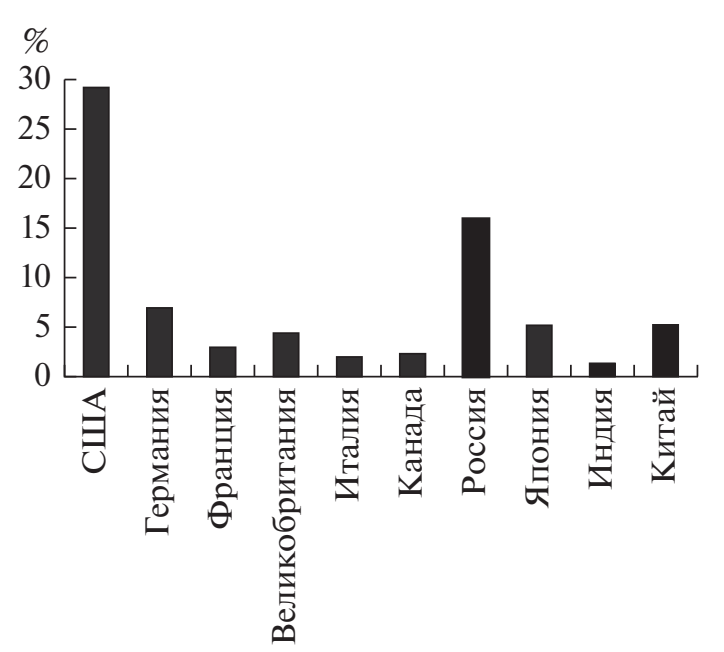

1970 г.

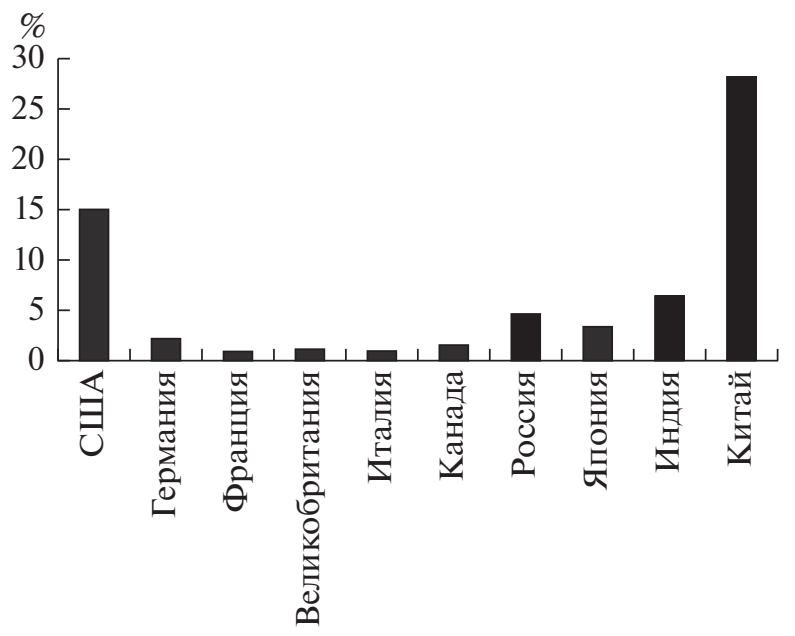

2015 г.

Рис. 2. Доля ключевых стран в эмиссии $\mathrm{CO}_{2}$. Рассчитано автором по: [21, 24].

Поэтому пока душевые показатели здесь сохраняются относительно высокие.

С 1970 по 2015 г. сильно изменился вклад стран Центра мирового хозяйства и его Полупериферии как в генерацию мирового ВВП, так и в мировую эмиссию $\mathrm{CO}_{2}$. В целом можно говорить о новой географии источников антропогенной эмиссии $\mathrm{CO}_{2}$, которая сложилась в процессе трансформации мирового хозяйства за последние полвека.

Конечно, по одному показателю антропогенных выбросов $\mathrm{CO}_{2}$, при всей его важности, нельзя судить об изменении всех параметров антропогенной нагрузки в различных регионах и странах мира. Нужно учитывать и то, что вне зависимости от приверженности или скептицизма в отношении гипотезы антропогенного глобального изменения климата, к нему привязаны в той или иной степени ряд других важных индикаторов антропогенной нагрузки и экологических характеристик хозяйства регионов и стран.

\section{НОВАЯ ГЕОГРАФИЯ ЦЕНТРОВ ЭКОЛОГИЧЕСКОГО \\ БЛАГОПОЛУЧИЯ/НЕБЛАГОПОЛУЧИЯ В МИРОВОМ ХОЗЯЙСТВЕ}

Далеко не все экологически значимые процессы в контексте глобального “геоэкологического перехода" синхронизированы в пространстве и времени. Например, пик обезлесения в Англии был достигнут еще в период “великого дровяного кризиса" 400 лет назад, в США - в начале 20 -х годов прошлого века. Но сегодня в трудах Н.А. Алексеевой говорится уже и о глобальном лесном переходе [5, стр. 55]. Есть и другие, на наш взгляд, исключительно важные тенденции. С 1990-х годов в мире не растет площадь сельскохозяйственных угодий [5, с. 19]. Не увеличивается с середины 1980-х годов и улов рыбы в мировом океане благодаря тому, что весь прирост производства рыбы и других даров океана обеспечивается аквакультурой [22].

Примерами выраженных экологически позитивных сдвигов, показывающих принципиальную возможность реализации идей известного доклада Римского клуба “Фактор четыре" 1997 г. (когда рост производства сопровождается существенным сокращением не только относительных, но и абсолютных экологических издержек), могут служить удаление тетраэтилсвинца из автомобильного топлива и хлорфторуглеродов из хладоагрегатов в большинстве стран мира, многократное сокращение выбросов серного ангидрида $\left(\mathrm{SO}_{3}\right)$ в США и странах Западной Европы.

По ряду экологических индикаторов (выбросы $\mathrm{CO}_{2}, \mathrm{SO}_{3}$, концентрация мелкодисперсных взвешенных частиц в воздухе (РМ 2.5), антропогенное химическое загрязнение водоемов и др.) за последние десятилетия тренды становятся все более разнонаправленными по регионам мира. Межррегиональные и межсттрановые сдвиги в экологической обстановке по параметрам загрязнения воздуха, воды и ряду других показателей экологического благополучия/неблагополучия в основном детерминированы трансформациями в географии мирового хозяйства, и в первую очередь в географии индустрии.

В высокоразвитых постиндустриальных странах мирового Центра экологически позитивные тренды выражены наиболее отчетливо. Они вполне вписываются в эколого-экономическую типологию стран мира Б.Н. Зимина, согласно которой в авангарде экологически позитивных сдвигов будут идти малые высокоразвитые страны [6, с. 139]. Сегодня это можно наблюдать на примере Швейцарии, Швеции, Норвегии, Сингапура и других ма- 
лых стран и микрогосударств мира с наивысшими значениями ВВП на душу населения. Показательна современная экологическая обстановка в городах, включая крупнейшие агломерации и мегалополисы. Наилучшие показатели по загрязнению воздуха в большинстве своем имеют города в высокоразвитых странах, наихудшие - в странах третьего мира. Это иллюстрирует ситуация с загрязнением $\mathrm{PM}_{2.5}$ городов мира. Из 200 городов с самым загрязненным взвесями воздухом подавляющее большинство расположены в Азии. Наибольшее число городов с наихудшими показателями по загрязнению воздуха - китайские и индийские [29].

Россия занимает особое, противоречивое место в системе координат экологического благополучия/неблагополучия стран на эколого-географической карте мира и в мировом хозяйстве. Как справедливо отмечает Н.Н. Клюев, "по широкому кругу параметров Россия относится к числу экологически благополучных стран планеты, ибо воздействия населения и хозяйства на природу приходятся на огромную территорию. Отечественные экологические проблемы, как правило, имеют локальный характер и часто связаны с высоким уровнем загрязнения атмосферного воздуха в городах" [2, с. 14]. За 1991-2016 гг. к хронически неблагополучным экстремально загрязненным городам нашей страны относятся Магнитогорск, Южно-Сахалинск, Братск и Чита. Вместе с этим, при учете численности населения городов и социальной опасности загрязнения атмосферы, по расчетам Н.Н. Клюева, приоритетными для решения проблем острых проблем загрязнения окружающей среды в городах должны быть крупнейшие города (Москва, Санкт-Петербург, Екатеринбург и др. [2, с. 17].

Похожие тренды с некоторыми вариациями можно наблюдать по индикаторам экологического состояния водных объектов и ряду других индикаторов благополучия/неблагополучия окружающей среды.

В целом, можно констатировать, что за последние полвека произошли качественные сдвиги в географии мирового хозяйства, которые повлекли за собой сдвиг главного очага экологического неблагополучия из стран традиционного Центра мирового хозяйства на его Полупериферию, которую формируют сравнительно более развитые из полупериферийных стран.

Сдвиг очага экологического неблагополучия в страны Полупериферии - это прежде всего следствие глобального сдвига промышленности в Восточную и Юго-Восточную Азию в процессе их догоняющего развития. Нынешняя волна индустриализации связана в первую очередь с Китаем, Индией, а также Республикой Корея. С 1950 по 2013 г. удельный вес стран Азии вырос: с 4 до 68\% в выплавке стали; практически с 0 до 58\% - в вы- пуске легковых автомобилей; с 5 до 55\% - в производстве минеральных удобрений; с 8 до $83 \%$ - в выпуске разного вида химических волокон [7]. Приведенные данные подтверждают факт пространственного перераспределения индустриального потенциала и производства между крупными регионами мира в пользу Азии. По своей природе это результат второй волны индустриализации, которая по своим масштабам не только не уступала первой, а по многим характеристикам стала еще более грандиозной, что повлекло за собой экологические последствия, соразмерные масштабу происходящего. Только один пример: если в 1970-е годы в мире производилось 600 млн т стали в год, а в стране-лидере (США) - 122 млн т, то в 2017 г. 1.6 млрд т в мире, и только один Китай произвел более 830 млн т. Даже с поправкой на более современные по экологическим характеристикам технологии в металлургической промышленности, они не способны пока остановить рост выбросов газов и пыли, так как продолжают использовать каменноугольный кокс.

Усугубляет сегодняшнюю экологическую ситуацию в Китае, а также в Индии отраслевая структура энергетики, где доля угля составляет пока около 60\% (правда с тенденцией к сокращению в рамках борьбы со смогом), в Индии - около 50\%. В обеих странах высокая доля угля в энергобалансе страны определяется его относительной дешевизной. По данным Рэнд Корпорэйшен, ущерб от загрязнения воздуха в Китае каждый год в период первого десятилетия нынешнего века был равен 6.5\% ВВП Китая. Аналогичный показатель, связанный с загрязнением воды и деградацией почв, составил соответственно дополнительные 2.1 и $1.1 \%$ ВВП [19].

Все больший вклад в ухудшение экологической обстановки в Китае вносит транспорт. В 2016 г. количество моторных транспортных средств в Китае достигло 300 млн, включая более 200 млн автомобилей. Регионы с наиболее грязным воздухом Китае: Пекин, Тяньцзинь, провинции Хэбэй, Шаньси, Шаньдун и Хэнань; они занимают вместе чуть более $7 \%$ территории страны, но именно в них сконцентрировано около трети всего китайского автопарка.

В целом страны мировой Полупериферии сегодня повторяют путь Центра, но с запаздыванием в 80-130 лет. При этом общие масштабы хозяйства в целом и промышленности в частности многократно возросли, как и антропогенное давление на окружающую среду. Нужно учитывать и то обстоятельство, что общий, пока отстающий от стран Центра мирового хозяйства уровень технологического развития, меньшая экологическая притязательность со стороны бедного в массе населения и более низкая общая экологическая культура мультиплицируют негативные экологические последствия стремительного роста новых экономических гигантов XXI в. 


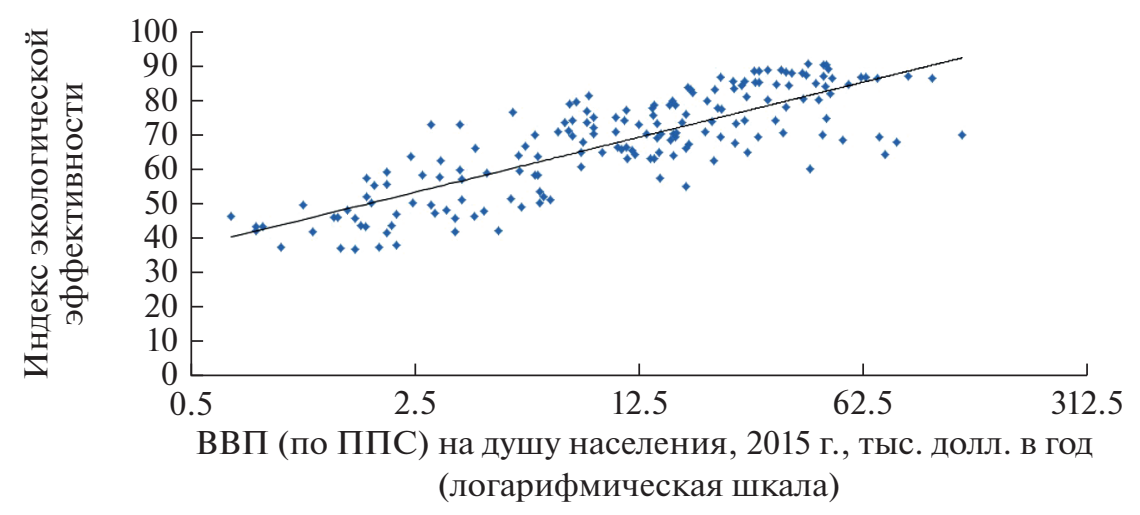

Рис. 3. Зависимость индекса экологической эффективности стран (Йельский университет) от уровня ВВП на душу населения. Рассчитано автором по: [19, 26].

\section{ЭКОНОМИКО-ГЕОГРАФИЧЕСКАЯ ИНТЕРПРЕТАЦИЯ КРИВОЙ С. КУЗНЕЦА}

Разнонаправленные экологические тренды в странах различного типа знаменуют начало нового цикла в развитии отношений между человеком и природой. Потребительские приоритеты богатого постиндустриального общества качественно меняют отношение к экологическим характеристикам территории. Состояние окружающей среды если оно обладает соответствующим качеством само по себе является потребительским благом. Улучшение этого состояния или хотя бы предотвращение его ухудшения создает, так же, как и вложения в человеческий капитал, в науку и образование, положительные внешние эффекты экстерналии. С ростом благосостояния общества, после того, как уровень развития достигает определенного значения, спрос на качество окружающей среды начинает расти. Он растет быстрее, чем спрос на товары и услуги в среднем. Эту гипотезу выдвинули Дж. Гроссман и А. Крюгер [11] на основе экологической интерпритации кривой С. Кузнеца [14]. В литературе эта кривая получила название “экологической кривой Кузнеца", хотя она до сих пор остается дискуссионной в среде экологов.

Сравнительный эколого-экономический анализ стран и макрорегионов мира, по мнению автора, в целом, подтверждает правоту С. Кузнеца. Об этом свидетельствует график экологической эффективности стран в 2015 г. авторитетного Иельского университета (рис. 3). Экологическая эффективность была рассчитана на основе 22 показателей, которые отражают различные аспекты состояния окружающей среды и жизнеспособности экосистем, сохранение биоразнообразия, экологическую оценку практики экономической деятельности в стране, а также эффективность государственной политики в области экологии. На графике хорошо видно, что индекс возрастает по мере роста душевого ВВП. Экологические характеристики окружающей среды становятся все бо- лее весомыми при интегральной оценке качества жизни. Если интерпретировать дрейф эпицентра экологического неблагополучия из высокоразвитых постиндустриальных стран Центра мирового хозяйства в страны динамично развивающейся Полупериферии, то первые теперь размещаются на нисходящей ветви кривой Кузнеца, а вторые на восходящей (рис. 4).

Можно оценить, при каком ВВП по ППС на душу населения наступает точка перегиба в кривой С. Кузнеца. Конечно, эти расчеты очень приблизительные, но, тем не менее, имеют определенный смысл для оценки общих перспектив развития экологической обстановки на планете на ближайшие десятилетия. Если исходить из того, что в наиболее высокоразвитых странах выраженные экологически позитивные тренды стали наблюдаться примерно в 1980-1990 гг., то речь идет о диапазоне от 10 до 20 тыс. долл. на человека в год (в ценах 2010 г.).

В Китае в 2018 г. ВВП (по ППС) на душу населения составлял примерно 8 тыс., в Индии - около 2 тыс. Если эти цифры интерпретировать с опорой на данную кривую, то Китай недалек от точки перегиба, и есть вероятность, что в ближайшие десятилетия экопозитивные тренды в этой стране начнут набирать все большие обороты. Это исключительно важно для общемирового развития с учетом веса Китая в народонаселении и современном мировом хозяйстве.

Статистика уже фиксирует ряд знаковых экологически позитивных сдвигов. Приведу некоторые из них: доля угля в энергообеспечении Китая за 2000-е годы сократилась с 72 до 59.8\%. Руководство КПК поставило задачу к 2020 г. на $50 \%$ сократить выбросы парниковых газов на производство единицы ВВП по сравнению с показателями 2005 г. В 2018 г. КНР обеспечила почти половину глобального роста производства альтернативной энергии и уже занимает первое место в мире по ее мощностям. Сокращение доли угля и активный переход на альтернативные источники 
энергии позволило Китаю стабилизировать выбросы парниковых газов, с 2016 г. наблюдается даже некоторое сокращение [27]. В стране развернута кампания по созданию “зеленой” финансовой и налоговой систем, системы мониторинга загрязнения городской среды. Борьба с загрязнением вошла в число так называемых "Трех великих битв” Китая. Трехлетний план по борьбе за чистоту воздуха включает в себя ликвидацию устаревших производственных мощностей, контроль за потреблением угля и стимулирование более частого использования железнодорожного транспорта для грузовых перевозок. В КНР разработана масштабная экологическая программа, согласно которой к 2020 г. будет засажено деревьями более четверти территории страны, сократится потребление воды на 23\%, энергии - на $15 \%$, выбросы углерода на единицу ВВП - на 40$45 \%$ по сравнению с уровнем 2005 г, выбросы $\mathrm{SO}_{2}$, оксидов азота и мелкодисперсных твердых частиц в морском секторе Китая должны быть снижены на 65, 20 и $30 \%$ соответственно по сравнению с показателями 2015 г. в трех прибрежных районах - дельтах рек Чжуцзян и Янцзы и заливе Бохайвань. Результатом должна стать новая, “Китайская экологическая цивилизация”.

Если в Китае уже видены первые признаки разворота в сторону экологизации хозяйства, то об Индии этого пока сказать нельзя. По расчетам Г.В. Сдасюк, доля расходов на охрану окружающей среды в бюджете Индии в 3.6 раза меньше, чем в Китае. (В КНР - 49.7 млрд юаней, или $0.061 \%$ ВВП, в Индии - 26.7 млрд рупий, или $0.017 \%$ ВВП страны). Исходя из кривой С. Кузнеца, для смены трендов в этой стране нужно пятикратное увеличение душевого ВВП. В условиях, когда население Индии растет намного динамичнее, чем в Китае, пятикратное увеличение ВВП на душу населения в ближайшие десятилетия маловероятно. С другой стороны, если активно развивающаяся Индия действительно совершит социально-экономический прорыв, масштаб экологически негативных последствий этого прорыва может оказаться еще более тяжелым для страны и всего мира, чем экологические издержки китайского экономического чуда.

\section{ВЫВОДЫ}

Усложнение связей между экономическим ростом и его экологическими последствиями на стыке столетий свидетельствует о начале качественно нового этапа в развитии мирового хозяйства и экологической обстановки на Земле. Глобальная экологическая обстановка в каждый конкретный период времени - результат огромного и сложнейшего букета природных и социальноэкономических процессов. Но можно увидеть, что среди них сегодня все отчетливее видятся экологически позитивные тренды. Принципи-
Общий уровень

экологических издержек

экономического развития

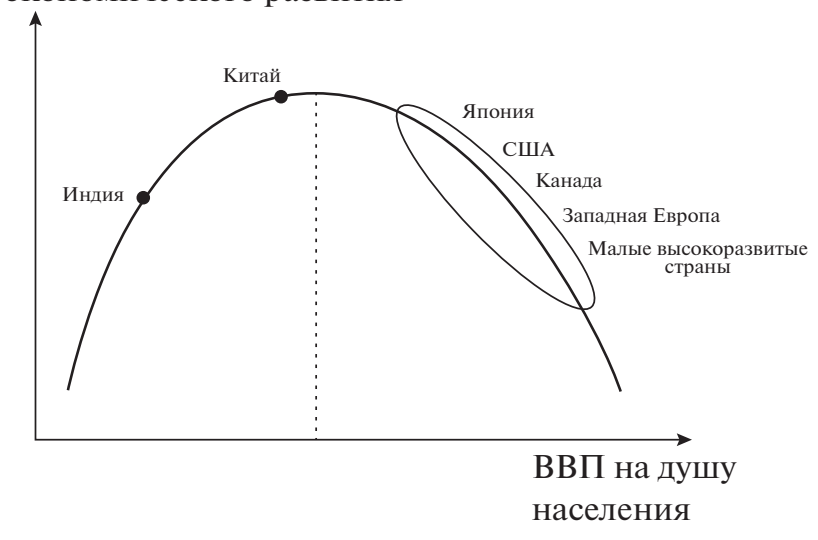

Рис. 4. Экономико-географическая интерпретация экологической кривой С. Кузнеца. Составлено автором.

ально важно то, что они детерминированы в первую очередь экономически и социально, и связаны с постиндустриальными процессами в мировом хозяйстве.

Новый, сложившийся постиндустриальный уклад в высокоразвитых странах Центра мирового хозяйства покончил с прямой зависимостью между экономическим ростом и его экологическими издержками. Ухудшение экологической обстановки в ядрах экономического развития во второй половине $\mathrm{XX}$ в. сменилось разнонаправленностью экологических трендов в макрорегионах мира в первые десятилетия XXI в.

Очагами догоняющей индустриализации выступили прежде всего страны Полупериферии, куда из стран Центра сместился главный очаг экологического неблагополучия на планете. В ближайшие десятилетия экологическая обстановка в мире пространственно будет все более и более усложняться, становясь все более мозаичной, что, возможно, знаменует начало глобального “геоэкологического перехода" в масштабах всего мирового хозяйства.

\section{ФИНАНСИРОВАНИЕ}

Статья подготовлена по материалам исследований в рамках государственного задания Института географии РАН № 0148-2019-0008.

\section{FUNDING}

The work was performed within the framework of the state-ordered research theme of the Institute of Geography RAS, no. 0148-2019-0008. 


\section{СПИСОК ЛИТЕРАТУРЫ}

1. Валлерстайн И. Экология и экономика в глобальном контексте // Вопросы экономики. 2004. Т. 27. № 4. C. $95-103$.

2. Клюев Н.Н. Качество атмосферного воздуха российских городов в 1991-2016 гг. // Изв. РАН. Сер. геогр. 2019. № 1. С. 14-23.

3. Курбатова А.И., Тарко А.М. Динамика выбросов парниковых газов в странах мира // Вестн. РУДН. 2015. Вып. 1. С. 117-123.

4. Медоуз Д. и др. Пределы роста. 30 лет спустя. М.: Академкнига, 2007. 342 с.

5. Мир геоэкологии. Геоэкологические проблемы и пути их решения: Сб. М.: МГУ-Варсон, 2004. 368 с.

6. Размешение промышленности в рыночной среде. Из трудов Б.Н. Зимина / Сост. А.П. Горкин, Ю.Г. Липец. М.: Альфа-М, 2003. 176 с.

7. Родионова И.А., Шувалова О.В. Глобальные тенденции развития мировой промышленности: монография. М.: РУДН, 2018. 111 с.

8. Саймон Джс. Неисчерпаемый ресурс. М.: Социум, 1966. $734 \mathrm{c}$.

9. Салысин В.И., Гулиев И.А., Мустафинов Р.К. Устойчивое развитие и текущее состояние энергетики стран Европейского Союза // Энергетический вестн. 2016. № 1. C. 60-71. https://doi.org/10.7256/2453-8892.2016.1.20714 http://www.nbpublish.com/library_read_article.php?id $=20714 \# 8$ (дата обращения 01.07.2019).

10. Хелд Д., Гольдблатт Д., Макгрю Э., Перратон Джс. Глобальные трансформации: политика, экономика, культура / Пер. с англ. М.: Праксис, 1999. 215 с.

11. Grossman G., Krueger A. Environmental Impacts of a North American Free Trade Agreemen // NBER Working Paper № 3914. Cambridge, MA: National Bureau of Economic Research, 1991. 57 p.

12. Dicken $P$. Global shift. Mapping the Changing Contours of the World Economy. SAGE, 2007. 599 p.

13. Kaika D., Zervas, E. The Environmental Kuznets Curve (EKC) theory // Energy Policy. 2013. V. 62. P. 1392-1411.

14. Kuznets $S$. Economic growth and income inequality // American Economic Rev. 1955. V. 45. № 1. P. 1-28.

15. Meadows D.H., Meadows D.L., Randers J., Behrens W.W. (1972). The Limits to Growth; A Report for the Club of Rome's Project on the Predicament of Mankind. NY: Univ. Books Publ., 1972. 200 p.
16. Shibayama K., Fraser I. Nonhomothetic growth models for the environmental Kuznets curve // Int. Econ. Rev. 2014. V. 55. № 3. P. 919-942.

17. Weizsäcker E.U., Lovins A.B., Lovins L.H. Factor Four: Doubling Wealth-Halving Resource Use. London: Earthscan, 1998. 322 p.

18. Yandle B., Vijayaraghavan M., Bhattarai M. The Environmental Kuznets Curve: A Primer The Property and Environment Research Center. 2002. PERC Res. Study 02-1.

19. China's Economic Rise: History, Trends, Challenges, and Implications for the United States. https://fas.org/sgp/crs/row/RL33534.pdf (дата обращения 05.09.2019).

20. Commission on Sustainable Development (CSD), United Nations. https://sustainabledevelopment.un.org/csd.html (дата обращения 01.07.2019).

21. СеоСайт. Динамика ВВП мира с 1970 по 2016 г. https://seosait.com/dinamika-vvp-mira-1970-2016/ (дата обращения 01.07.2019).

22. Состояние мирового рыболовства и аквакультуры. ФАО ООН. 216 c. http://www.fao.org/3/a-i5555r.pdf (дата обращения 05.09.2019).

23. National accounts - Analisis of Main Aggregates (AMA). Department of Economic and Social Affairs, United Nations. https://unstats.un.org/unsd/snaama/Index (дата обрашения 01.07.2019).

24. Мир на пороге зеленой революции. НИУ ВШЭ. https://www.hse.ru/news/188171386.html (дата обращения 01.07.2019).

25. Each Country's Share of $\mathrm{CO}_{2}$ Emissions. Union of Concerned Scientists. https://www.ucsusa.org/globalwarming/science-and-impacts/science/each-countrysshare-of-co2.html\#.W GCnugzaUl (дата обращения 01.07.2019)

26. Roser M., Ritchie H. $\mathrm{CO}_{2}$ and other Greenhouse Gas Emissions. Our World in Data. Retrieved. 2017. https://ourworldindata.org/co2-and-other-greenhouse-gas-emissions (дата обрашения 01.09.2019).

27. Sayt EKD (Noticias de China en ruso, julio 2017). http://ekd.me/2017/07/dolya-uglya-v-energopotrebleniiknr-upala-nizhe-60/ (дата обращения 01.08.2019).

28. Indice de eficiencia ambiental de la Universidad de Yale (EE.UU., 2018). https://nonews.co/directory/lists/countries/ecology (дата обращения 01.08.2019).

29. WHO Global Ambient Air Quality Database. Update 2918. https://www.who.int/airpollution/data/cities/en/ (дата обращения 05.09.2019).

\title{
Migration of the Center of the Ecological Trouble and Geo-Ecological Transition
}

\author{
D. L. Lopatnikov* \\ Institute of Geography, Russian Academy of Sciences, Moscow, Russia \\ *e-mail:imartos@mail.ru
}

\begin{abstract}
The ecological situation deterioration in the cores of economic development in the second half of the 20th century was replaced by a multidirectional environmental trends in the macroregions of the World in the first decades of the 21st century. Interregional and cross-country shifts in the environmental situation are closely linked to transformations in the geography of the World economy. The post-industrial structure in the highly developed countries has ended the direct relationship between economic growth and its environmental costs. Environmentally positive trends in these countries are determined by economic and social factors. The countries of the world's Semi-Periphery have become hotbeds of catching-up industrialization, to which the main focus of environmental problems on the planet has shifted from the countries of the Center of the World economy. The increasing complexity of the relationship between economic growth and its environmental conse-
\end{abstract}


quences at the turn of the century indicates the beginning of a qualitatively new stage in the development of the World economy and the environmental situation on the Earth. In the coming decades, the environmental situation in the World will become spatially more complex, becoming more and more mosaic, possibly marking the beginning of a global geo-ecological transition of the entire World economy.

Keywords: geoecology, $\mathrm{CO}_{2}$ emission, territorial organization of the world economy, ecological problems, ecologization

\section{REFERENCES}

1. Wallerstein I. The ecology and the economy: What is rational? Review (Fernand Braudel Center), 2004, vol. 27 , no. 4 , pp. 573-583.

2. Klyuev N.N. The quality of atmospheric air of Russian cities in the years 1991-2016. Izv. Akad. Nauk, Ser. Geogr., 2019, no. 1, pp. 14-23. (In Russ.).

3. Kurbatova A.I., Tarko A.M. Dynamics of greenhouse gasses emissions in the countries of the World. Vestn. RUDN, 2015, no. 1, pp. 117-123. (In Russ.).

4. Meadows D., Randers J. Limits to Growth: The 30-Year Update. Chelsea Green Publ., 2004. 368 p.

5. Mir geoekologii. Geoekologicheskie problemy i puti ikh resheniya [The World of Geoecology. Geoecological Problems and Ways to Solve them]. Moscow: MGUVarson Publ., 2017. 320 p.

6. Razmeshchenie promyshlennosti v rynochnoi srede. Iz trudov B.N. Zimina [Location of Industry in a Market Environment. From the Works of B.N. Zimin]. Gorkin A.P., Lipets U.G., Eds. Moscow: Alfa-M Publ., 2003. 176 p.

7. Rodionova I.A., Shuvalova O.V. Global'nye tendentsii razvitiya mirovoi promyshlennosti [Global Trends of World Industry Development]. Moscow: RUDN, 2018. $111 \mathrm{p}$.

8. Simon J.L. The Ultimate Resource 2. Princeton, NJ: Princeton Univ. Press, 1966. 734 p.

9. Salygin V.I., Guliev I.A., Mustafaev R.K. Sustainable development and the current state of the energy sector of the countries of the European Union. Energeticheskii Vestn., 2016, no. 1, pp. 60-71. doi 10.7256/24538892.2016.1.20714

10. Held D., Goldblatt D., McGrew E., Perraton J. Global Transformations: Politics, Economy, Culture. Stanford University Press, 1999. 215 p.

11. Grossman G., Krueger A. Environmental Impacts of a North American Free Trade Agreement. NBER Working Paper no. 3914. Cambridge, MA: National Bureau of Economic Research, 1991. 57 p.

12. Dicken P. Global Shift. Mapping the Changing Contours of the World Economy. SAGE, 2007. 599 p.

13. Kaika, D., Zervas, E. The Environmental Kuznets Curve (EKC) theory. Energy Policy, 2013, vol. 62, pp. 1392-1411.

14. Kuznets S. Economic growth and income inequality. Am. Econ. Rev., 1955, vol. 45, no. 1, pp. 1-28.

15. Meadows D.H., Meadows D.L., Randers J., Behrens W.W. The Limits to Growth; A Report for the Club of Rome's Project on the Predicament of Mankind. N.Y.: Universe Books Publ., 1972. 200 p.

16. Shibayama K., Fraser I. Nonhomothetic growth models for the environmental Kuznets curve. Int. Econ. Rev., 2014, vol. 55, no. 3, pp. 919-942.

17. Weizsäcker E.U., Lovins A.B., Lovins L.H. Factor Four: Doubling Wealth-Halving Resource Use. London: Earthscan, 1998. 322 p.
18. Yandle B., Vijayaraghavan M., Bhattarai M. The Environmental Kuznets Curve: A Primer. PERC Research Study 02-1. 2002. Available at: https://www.perc. org/wp-content/uploads/old/Yandle_Kuznets02.pdf (accessed: 05.07.2020).

19. China's Economic Rise: History, Trends, Challenges, and Implications for the United States. CRS Report, prepared for Members and Committees of Congress. 2019. Available at: https://fas.org/sgp/crs/row/RL33534.pdf (accessed: 05.09.2019).

20. Commission on Sustainable Development (CSD), United Nations. Available at: https://sustainabledevelopment.un.org/csd.html (accessed: 01.07.2019).

21. The Dynamics of World GDP from 1970 to 2016. Available at: https://seosait.com/dinamika-vvp-mira-19702016/ (accessed: 01.07.2019). (In. Russ.).

22. State of the World's Fisheries and Aquaculture. FAO, UN, 2016. 216 p. Available at: http://www.fao.org/3/ai5555e.pdf (accessed: 05.09.2019).

23. National accounts - Analysis of Main Aggregates (AMA). Department of Economic and Social Affairs, United Nations. Available at: https://unstats.un.org/unsd/snaama/Index. (accessed: 01.07.2019).

24. World on the Verge of a Green Revolution. HSE. Available at: https://www.hse.ru/news/188171386.html (accessed: 01.07.2019). (In Russ.).

25. Each Country's Share of $\mathrm{CO}_{2}$ Emissions. Union of Concerned Scientists, 2020. Available at: https://www.ucsusa.org/global-warming/science-andimpacts/science/each-countrys-share-of-co2.html\#. W_GCnugzaUl (accessed: 01.07.2019).

26. Roser M., Ritchie H. $\mathrm{CO}_{2}$ and other Greenhouse Gas Emissions. Our World in Data, 2017. Available at: https://ourworldindata.org/co2-and-other-greenhousegas-emissions\#per-capita-co2-emissions (accessed: 01.09.2019).

27. The Share of Coal in China's Energy Consumption Fell below 60\%. EKD, 24.07.2017. Available at: http:// ekd.me/2017/07/dolya-uglya-v-energopotreblenii-knrupala-nizhe-60. (accessed: 01.08.2019). (In Russ.).

28. Indice de eficiencia ambiental de la Universidad de Yale (EE.UU., 2018) Available at: https://nonews.co/directory/lists/countries/ecology (accessed: 01.08.2019).

29. WHO Global Ambient Air Quality Database. Update 2918. Available at: https://www.who.int/airpollution/data/cities/en/ (accessed: 05.09.2019). 